\title{
Gender and Police Response to Domestic Violence
}

\section{Monica Fagerlund}

Institute of Criminology and Legal Policy, University of Helsinki, Helsinki, Finland;

RDI-Department, Police University College of Finland, Tampere, Finland

University of Helsinki, Institute of Criminology and Legal Policy, P.O. Box 16, 00014

University of Helsinki, monica.fagerlund@helsinki.fi

Acknowledgements: The author would like to thank the anonymous reviewers for their constructive criticism, Dr Noora Ellonen and Dr Juha Kääriäinen for comments on the earlier versions of this article, and Kari Pylväs, a colleague from the Police University College, for comments, proofreading and for help with the graphic design.

Funding: This work was supported by the Ministry of Interior, Administration and Development Department [SMD-no2014-1786]; Ministry of Interior, Police Department [SMDno2014-2733].

The Version of Record of this manuscript has been published and is available in Police Practice and Research, Apr 7th 2020, http://www.tandfonline.com/10.1080/15614263.2020.1749622. 


\section{Gender and Police Response to Domestic Violence}

The gendered profession of police, as well as domestic violence as a societal problem, is central to the discussion surrounding gender and equality and forms a strongly debated foundation of research. This paper presents empirical findings from the associations between gender and police response to domestic violence in Finland. The data is a rare combination of official police data and survey data from frontline police and includes 410 police emergency call-outs. The results indicate that the combination of a male victim and two male police officers is the least likely to result in the recording of an offence, arrest, or referral to support services. Findings are examined in comparison to prior research concerning police response to domestic violence, and implications for policy and practice are discussed. The study raises issues about gender and policing that should also be examined in other countries and jurisdictions in relation to policing domestic violence.

Keywords: police response; domestic violence; gender; discretion

\section{Introduction}

Descriptions of a law enforcement (or police) officer often include references to masculinity, aggression and physical power (Jordan, 2002; Rabe-Hemp, 2007). In the literature that examines violence from a gender perspective, these attributes and the male gender have also been associated with the perpetration of domestic violence (DV) (Anderson \& Umberson, 2001; Bates, Kaye, \& Pennington, 2019). Most firstresponders to DV incidents are men (i.e. police officers), and, based on both reporting rates to police in victimisation surveys (e.g. Danielsson \& Salmi, 2013; MacQueen \& Norris, 2016) and the gender distribution of victims in police records (Brown, 2004; Aaltonen, Salmi, \& Kivivuori, 2014), most victims who call for help in these situations are women. Furthermore, policy programmes, interventions, and the work of service providers are designed to deal with DV as violence perpetrated by men against women

(Brown, 2004; Dobash \& Dobash, 2004; Douglas \& Hines, 2011). The understanding of 
such violence as a gendered phenomenon leads to less identification of male victimisation and female perpetration (Bates et al., 2019). Therefore, policing DV requires special attention with regard to gender perspective.

In general, women are more likely to experience violence at home and by perpetrators known to them, whereas men are more likely to be victimised by strangers outside their home (e.g. Danielsson \& Kääriäinen, 2017; Davies, 2011). Both women and men tend to underreport their victimisation and any injuries resulting from it, but both types of underreporting are more likely for men than women (Brown, 2004, p. 6; Danielsson \& Salmi, 2013). While child victims of DV are becoming better recognised (Elliffe \& Holt, 2019; Richardson-Foster et al., 2012), social norms may continue to obscure women as perpetrators (Bates et al., 2019), as well as child-to-parent violence and the related gender effects that exist in this blind spot of DV research (Armstrong, Muftic, \& Bouffard, 2018; Strom, Warner, Tichavsky, \& Zahn, 2014).

As the first responders to DV and often arbitrators of violent situations, police officers work on the frontline against DV. Since the 1980s, the effects of police response to DV, particularly arrest, have been studied repeatedly (e.g. Felson et al., 2005; Frye, Haviland, \& Rajah, 2007; Robinson, 2000; Sherman \& Berk, 1984). Another line of research has focused on factors associated with variation in police responses to DV (e.g. Barrett, Pierre, \& Vaillancourt, 2011; Lee et al., 2013; Novak, Brown, \& Frank, 2011; Robinson \& Chandek, 2000). More recently, however, police response to DV has received surprisingly little research interest (Myhill, 2019). Furthermore, research from the perspective of gender-including other police responses besides arrest for DV-is scarce. The current study attempts to address these shortcomings. 
In this study, police DV call-out data from the Police and Emergency Response Centre (ERC) database in Finland is merged with survey responses from the police officers who attended those same call-outs in order to examine possible gender effects in police response to DV. By referencing official data from the ERC and police database with police survey responses on actual call-outs, the study aims at to overcome the difficulties related to the hypothetical nature of DV incidents and police actions, as the police answered questions about actual call-outs that occurred. Furthermore, because the analysis does not rely solely on official police data produced for other purposes than research, it provides a particularly strong source of information.

In order to place this study within the broader context of gender and DV studies, prior research and the main data sources are briefly discussed, with references to key indicators in Finland. Findings from previous studies on police responses to DV are briefly reviewed. The paper then proceeds to the data and methods of the empirical part of this study, presenting the results, discussing limitations, and finally concluding with implications for policy, training, and practice.

\section{Gender and DV}

The considerable body of research about victims of DV and their gender presents varying and contradictory findings. Two central sources of information on victimisation of DV, victim surveys and official police statistics, form differing pictures of the gender distribution of victimisation. Lethal violence as the extreme form of DV includes predominantly male perpetrators and female victims (Corradi \& Stöckl, 2014). Statistics based on police records show that more than $80 \%$ of offenders in DV crimes in Finland are men (Aaltonen et al., 2014). Victimisation surveys, however, offer varying estimates depending on the specific methodology. 
With the general crime victim perspective, focusing on the prevalence of victimisation to acts defined as criminal and involving nationally representative samples of both women and men, the results from the Finnish National Crime Victim Surveys (NCVS) show moderate differences between genders. Five percent of women and 3\% of men reported having experienced physical DV perpetrated by their current or former partner over the past 12 months (Danielsson \& Kääriäinen 2017, p. 13). Based on these most recent NCVS results, there are no statistically significant differences between women and men in Finland in victimisation of more serious forms of physical violence, which involve at least slapping. The difference in victimisation to DV was mostly connected to women's more common experiences of being stopped from moving, grabbed, and pushed.

A victimisation survey designed specifically to examine men's violence against women (VAW) showed remarkably higher numbers compared to NCVS. In a survey conducted in 2005, 18\% of Finnish women reported experiencing physical DV during the past 12 months (Piispa et al., 2006). As a VAW survey, however, the latter does not enable comparisons in relation to gender. In addition, it should be noted that gender framing as a survey methodology to specifically examine men's violence against women may increase participants' proneness to report borderline incidents in a survey setting (Kivivuori, Danielsson \& Sirén, 2012).

With regard to differences between genders in victimisation, indications of women sustaining injuries more often and being fearful due to DV have been reported (Dobash \& Dobash, 2004; Johnson, 2010). A victimisation survey including both women and men in Finland also indicated that women are more likely than men to report both the physical and psychological consequences of DV (Heiskanen \& Ruuskanen, 2011). Based on a thorough analysis of Canadian data from cases of DV 
that came to the attention of the police, Brown (2004) found that men experienced severe physical violence more often than women. In an examination of dyadic types of partner violence, both partners have been found to commit assault in around half of the cases, while the remaining proportion of the male-only and female-only types occurred equally (Langhinrichsen-Rohling et al., 2012; Straus \& Michel-Smith, 2014).

Several studies have indicated that men are more likely to refrain from reporting DV to the police (Brown, 2004; Danielsson \& Salmi, 2013; MacQueen \& Norris, 2016) or seeking help (Galdas et al., 2005). In accordance with gender framing DV primarily as men's violence against women (Houston, 2019), male victims of DV face serious problems in recognising themselves as victims, being recognised as victims rather than perpetrators by other people, and receiving support services (Huntley et al., 2019). Accordingly, Felson and others (2015) deduce that violence against women is condemned more severely compared to violence against men, especially when perpetrators are men. Furthermore, results from the NCVS suggest that $10 \%$ of DV against women and 3\% against men in Finland is reported to the police (Danielsson \& Salmi, 2013). Men are less likely to report DV perpetrated against them to the police, meaning that official police statistics are likely to be more representative of men's violence against women compared to women's violence against men. Corporal punishment of children has been banned in Finland since 1984 and has since decreased remarkably, while still being relatively common (Fagerlund et al., 2014). A lot of violence against children still does not come to the attention of the authorities (Kuoppamäki, Kääriäinen, \& Ellonen, 2011).

The often-cited study by Dobash and Dobash (2004) aimed to 'unravel the puzzle' (p. 324) of the most common victims of DV. Dobash and Dobash (2004) acknowledged that men and women have different understandings of what constitutes 
violence, thus resulting in disagreement over the occurrence and frequency of it (see also Brown, 2004, p. 6). However, their choice of studying women's violence against men in the context of men's violence, that is, drawing a sample of couples based on males who had been convicted for using violence against their female partners, creates a bias in the assessment of symmetry and asymmetry in DV perpetrated by men and women. Still, Dobash and Dobash (2004) concluded that 'serious intimate partner violence is asymmetrical, with men usually violent to women' (p. 343).

It has also been suggested that the degree of gender symmetry varies across types of DV, with the most common type of violence, situational couple violence, being symmetrically perpetrated by women and men, whereas asymmetry may be more distinctive to intimate terrorism and violent resistance (Muftić et al., 2015). Situational couple violence was conceptualised by Johnson and Leone (2005) and described as an escalation of arguments to violence rather than a pattern of control over one's partner, latter being more commonly connected to intimate terrorism.

The notion that men and women may have differing views of what constitutes violence (Brown, 2004; Dobash \& Dobash, 2004) should be considered when assessing self-reporting of DV, as well as police response to DV. Recognising DV as requiring intervention by law enforcement has demanded a change in attitudes towards violence in close relationships, shifting from a private matter to a crime. However, gendered views concerning victimisation and perpetration of violence (Bates et al., 2019) have seemingly not changed as much as the condemnation of DV in general. Even though DV is now commonly understood as a serious societal problem in Western societies, male victims of DV still do not fit into the dominant theoretical perspective that views patriarchy as the cause of such violence (Douglas \& Hines, 2011). The social stigma related to men as victims of DV is also assessed to be greater compared to women as 
victims of DV, as men are 'intensely socialised from a very young age to suppress their fears, their pain and their suffering' (Brown, 2004, p. 7). Male victimisation to DV, therefore, remains a somewhat taboo topic (Arnocky \& Vaillancourt, 2014).

\section{Police Response to DV}

In relation to policing DV, it is problematic that police work is considered 'one of the most masculinized occupations' (Sun, 2007, p. 585), with police culture glorifying violence and promoting a 'cult of masculinity' (Dick \& Jankowicz, 2001; Prokos \& Padavic, 2002; Rabe-Hemp, 2007; Waddington, 1999). With such a backdrop, one could expect that police encounters with DV issues may be problematic. Before the 1980s, an overall reluctance to regard DV call-outs as real police work was found in many Western societies. Some studies have shown that the police were unwilling to intervene due to beliefs that women were responsible for triggering men's violence against them (Newbold \& Cross, 2008). However, later research has challenged this view of a 'sexist organisational culture dismissive of interpersonal violence' (Grant \& Rowe, 2011, p. 62; Myhill, 2019). Waddington (1999) stated that the sexism identified among police is widespread in society in general and found in many other occupations as well; 'This is not to excuse police sexism, but to merely point out that what police share in common with much of the population cannot be explained by social forms police sub-culture - that are purportedly distinctive to them' (Waddington 1999, p. 291).

Stewart and Maddren (1997) used hypothetical vignettes on DV to examine police officers' attitudes toward DV incidents. Within this setting, they found more reluctance among the police to be involved with DV incidents with a male victim compared to a female victim. Using a sample of 9,184 DV incidents reported to the 
Houston Police Department in 2005, Lee and others (2013) found that the police were less likely to make an arrest when the incident involved a same-sex couple or a male victim and a female assailant compared to incidents involving a female victim and a male assailant.

A recent study by Myhill (2019) revisited Hoyle's (1998) research frame on police attitudes and decisions concerning arrest and found that mandatory and presumptive arrest policies likely have had an effect on both over the past 20 years. The officers were more concerned than before about official policies and supervisory control on DV incidents. Consistent with prior findings, clear evidence of a serious criminal offence, risk assessment of serious harm to the victim, and a perpetrator's belligerent behaviour tended to result in arrest. Importantly, Myhill (2019) also concluded that presumptive arrest policies accompanied by organisational instructions may subvert individual differences in police attitudes towards DV.

A study by Fagerlund and others (2018) examined legal and extra-legal factors associated with recording an offence on police DV call-outs. In addition to severity and the likelihood of violence, informant position and the victim being female increased the likelihood of recording an offence significantly. This would seem to suggest that, in relation to several situational factors, the female gender of a victim had an independent effect on increasing the likelihood of recording DV as an offence.

The attention paid to children in policing DV has also grown over the past few decades in the United Kingdom and United States (Richardson-Foster et al., 2012). However, violence against and between children is still generally overlooked, resulting in only a small proportion of violence against children being reported to the authorities (Kuoppamäki, Kääriäinen, \& Ellonen, 2011). There also appears to be a gap in the examination of potential gender differences in police response to DV involving children 
(Strom et al., 2014) and a reluctance to intervene in child maltreatment among those examining DV from a gender perspective, even though mothers are as likely or even more likely than fathers to mistreat their children (Houston, 2018).

In one of the few studies addressing these issues, Richardson-Foster and others (2012) found that the police are better prepared for interacting with children and young people in other contexts than DV, for instance, in cases of children's antisocial behaviour. They point out the exclusion of children as victims and key actors in policing $\mathrm{DV}$, and conclude that there is a need for a policy that includes all children as victims of DV instead of focusing on women and girls. Furthermore, Armstrong and others (2018) stated that child-to-parent violence (CPV) is particularly challenging for policing because of victims' extreme reluctance to engage. They also found a gender effect in police responses in that 'male aggressors are more often criminalized through arrest when the victim is female (i.e., mother). Yet, male aggressors are no more likely than females to be arrested when they victimize a male (i.e., father)' (Armstrong et al., 2018, p. 11). Their findings suggest that, in policing DV, gender stereotypes may be relevant not only concerning partner violence, but also in violence between children and parents.

When analysing police officer performance by gender, two main explanatory models can be identified (Novak et al., 2010; Sun, 2007). First, the 'sameness' approach sees men and women as being generally the same when they are treated the same. Theories embracing this approach suggest that 'women and men behave similarly when they have equal access to power and opportunity and are proportionally represented' (Sun, 2007, p. 584). Therefore, arguably, women and men in law enforcement would employ similar responses to DV when they are similarly socialised into the masculine police culture. However, as women tend to be underrepresented in the higher ranks of 
the police, their (non)access to power in their profession may result in an intervening factor between gender and the execution of their job (Dick \& Jankowicz, 2001).

Second, the 'difference' approach sees men and women as fundamentally different due to their socialisation into gender groups, and as a consequence, their response to DV would also be different (Novak et al., 2010; Sun, 2007). Women are assumed to weigh the impact of their actions upon others more because of their socialisation into 'nurturing roles,' whereas men are seen as concentrating more on rules and being socialised into an 'ethic of justice' (Sun 2007, p. 584). Assuming a genderspecific style of policing, female officers are expected to be 'less physically aggressive, better verbal communicators, and be more nurturing and supporting' (Novak et al., 2011, p. 570, see also Rabe-Hemp, 2007). Sun (2007) hypothesised that, on one hand, female police officers would stress supportive and non-coercive responses to DV, and on the other, that they would see DV as a more serious violation compared to their male counterparts. Male police officers are assumed to possess more traditional views in considering DV as a private matter rather than a police matter. However, it has also been suggested that some women adapt to the masculine profession of law enforcement by exhibiting more extreme attitudes and behaviour than men as a means of proving their suitability to being police officers (Jordan, 2002). This might also result in harsh treatment of DV victims, both male and female, by female police officers.

\section{The Current Study}

This study examines the associations between gender and police response on police DV call-outs of one police department in Finland. In this paper, it is examined whether the genders of the victim, assailant, the police, and specific combinations of these factors are associated with certain police responses to DV? And if so, what are the associations 
between gender and police response to DV?

DV can be further divided into that between current and former partners and between other family members (Walby, Towers, \& Francis, 2014). Due to Finnish legislation and official instructions of the police, DV is here defined broadly and analysed as violence in close relationships. Described as part of the right to bring charges for petty assaults, the defining factor has, since the 2011 Criminal Code reform, been a close relationship (Ministry of Justice, 2012). This legal reform was aimed at removing the burden from the victim to demand a record of an offence and pressing charges for DV in a similar manner to pro-arrest and mandatory arrest policies used in the US and many other Western jurisdictions (Aaltonen et al., 2014; Fagerlund et al., 2018). Bringing petty assaults under public prosecution reduced the victim's discretion in deciding whether to pursue criminal investigation with the purpose of preventing future attacks (Aaltonen et al., 2014). Petty assaults are now subject to public prosecution in cases where the victim is:

[T] he offender's spouse or former spouse, sibling or direct ascending or descending relative or a person who lives or has lived in a joint household with the offender, or otherwise is or has been in a corresponding personal relationship with the offender or is close to him or her. (Ministry of Justice, 2012.)

Therefore, the Finnish policy concerning violence in close relationships is similar for parent-to-child, child-to-parent, and intimate partner violence. Additionally, violence involving child victims and child witnesses should initiate child protection measures, irrespective of the criminal justice procedure.

A different term related to violence in close relationships is used in the instructions and information systems for the ERC and the police; the Finnish word used 
in these most accurately translates to English as family violence. The definition of family violence task is "violence or noises referring to violence in an apartment. The parties are not necessarily family members' (National Police Board, 2014). Despite the naming of the task category, the main purpose of it is to inform the police that the scene of possibly violent acts is a private apartment or a house. This has different implications for police operational preparation in comparison to, for instance, a task involving a violent person in a public place. However, the police and the ERC data system does not systematically include information about the specific relationship between parties of violence because in many cases it can only be verified by the police who visited the scene. Therefore, we need information gathered from the police officers assigned to those tasks on the specific relationship between the people involved in order to find out if the task actually included a close relationship between the parties of violence as defined in the Criminal Code.

There is no unanimous agreement on the type and form of violence that should be covered within the concept of DV, making it particularly challenging to compare studies conducted from different theoretical perspectives. In the current study, we focus on police response to DV in Finland, which outlines the research within the frame of types of violence that are not a complainant offences in Finland. This is because, in cases of complainant offences, such as illegal threats that are emotional/psychological violence, police response is almost entirely tied to the victim's willingness to report and demand consequences for the assailant, which sets a different normative and legal context for police response. The type of violent acts covered in this study are discussed in detail in the measures section below. For the purpose of this study and for its international audience, domestic violence (DV) is used herein in the broad meaning of 
violence in close relationships as explained above, unless directly citing the terms used in other studies.

\section{Data}

The National Police Board granted permission for the data collection. The starting point for data collection were all the DV emergency calls in one police department area in Finland between April and September $2015(\mathrm{~N}=1,811)$. The time frame was chosen to cover the seasonal variation in police assignments while minimising the strain on the police caused by the data collection. The collection and outlining of the data is presented in the Figure 1.

Not all calls are deemed as urgent by the ERC, for instance, those violent incidents that occurred a week before the person makes the call, meaning their life and wellbeing is not presently or actively threatened. Persons calling for non-urgent matters are instructed to file a crime report at a police station. The data subset only includes calls that resulted in police intervention and excludes those deemed unurgent or otherwise not needing a police response by either the ERC or the police. Some tasks were recorded in the data system twice due to system error and, for some, the information about the police patrol on task had not been saved; thus, those 29 cases were not included in the data.

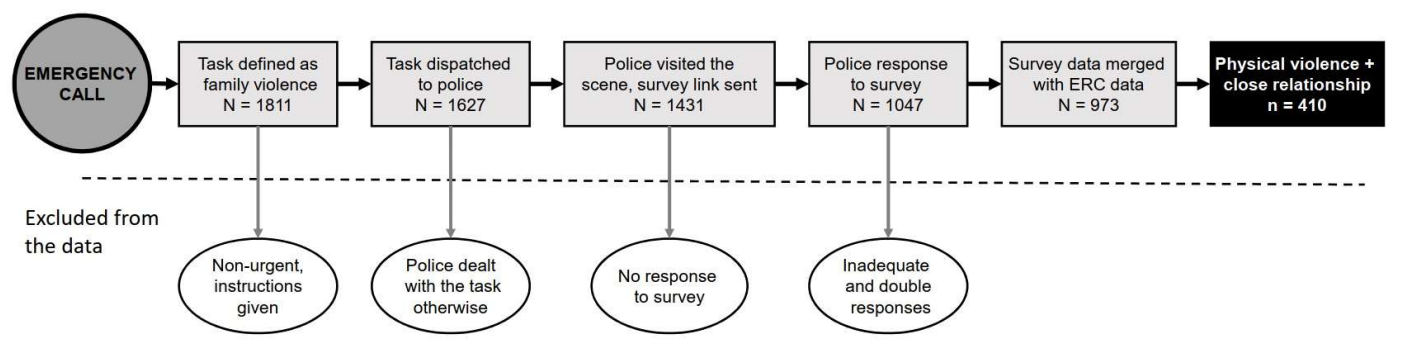

Figure 1. Data outlining process. 
The DV call-out data remaining after the first outlining (1,431 DV call-outs) was used to collect survey responses from the police officers who responded to those incidents. The survey responses were gathered via a web-based survey and phone interviews. The police were informed about the survey and the project in their internal notices via the intranet, and the commanding officer of the surveillance and emergency operations unit also sent informing emails. Participation was voluntary, and no incentives were used, except that responding to the survey was included in the working hours.

The names of the patrol officers were only used by the researcher to reach them via their professional email addresses. Since most DV call-outs occur during late hours and weekends, the emails were usually sent on the following workday during business hours. The email was sent to both officers of the two-officer patrols once, of which the patrol leader was primarily encouraged to respond. Names and other identifying information, except gender of the officers, were not included in the data. No personal information about the police officers were gathered in the survey in order to maximise anonymity and response rate.

The unit of analysis was the call-out task, and, therefore, the same police officers could be respondents for several tasks during the six-month data collection period. On average, the survey responses were received within eight days after the callout. The call information and survey responses were referenced using a detailed date and time coding of each call-out. Even though patrol leaders were the ones primarily encouraged to respond, for some call-outs, responses from both of the two patrol officers were received. Only one survey response could be paired with each call-out from the ERC and police data system, so duplicates were removed preferring the first received survey response before creating the final data. First responses were preferred 
due to reliability of memories after less time had passed after the call-out. Some officers did not copy and paste the specific date and time identifier of the task to the survey to enable the merging of data, and these insufficient survey responses had to be removed. After removing duplicates and insufficient survey responses for merging, the response rate was $68 \%$, or $973 \mathrm{DV}$ call-outs with referenced survey responses.

As mentioned above in the definition of police DV tasks, the actual relationship between the people involved can often only be determined by the officers who visited the scene. Therefore, the relationship between the people involved was asked after in the survey. Strangers and acquaintances were excluded for this analysis because these would not constitute as close relationships. The final data consists of 410 DV call-outs, in which a survey response was received, and a close relationship as well as physical violence, was reported by the police. Excluded data units therefore involved nonphysical violence and violence between strangers and acquaintances.

The most common police responses to DV were, in the following order, 'written recording of an offence,' 'task completed at the scene: otherwise,' and 'arrest.' The number of responses related to the recording of offences and arrest enabled to analyse the call-outs by victim, assailant, and police gender. These responses were not mutually exclusive, as a call-out could include both an arrest and recording of an offence. In contrast, the rather uninformative 'completing the task otherwise' translates to police visiting the scene, calming the situation, and making observations but taking no further actions (Fagerlund, 2016). Informing the victims about support services is an unofficial response that could not be measured based on official records. Referencing victims and perpetrators of violence to services may, however, be an important intervention in police response to DV. Therefore, informing people about support services was analysed as a third police action on these tasks. 
The data is a distinctive combination of official and partially automatic records and police survey data. Official reports and records are not generally designed for research purposes, and studies based on the use of police reports, officer surveys, or self-reported actions to hypothetical scenarios have been criticised for being unlikely to produce truthful results on police response to DV (e.g. Sun, 2007.) Officer surveys about hypothetical cases may produce socially desirable answers, with respondents finding it difficult to know how they would actually act in certain situations. Therefore, by referencing official data from the ERC and police database with police survey responses on actual call-outs, this research setting mitigates the difficulties related to the hypothetical nature of the DV incidents and police actions, as the police answered about actual DV call-outs.

The nature of the analysis is descriptive. Associations between gender and police responses are analysed using cross-tabulation and statistical testing with a Chisquare test. Cramer's V is reported as indicating the strength of the effect between variables.

Variables

Gender of the victim. Information concerning the suspected victim's gender is based on the questionnaire answered by the police officers that responded to the DV call-outs. The enquiry focused on the primary victim, whom the police officers defined as having suffered the most severe violence. All gender variables were only available dichotomously (female/male), and, therefore, transgender, other genders, and unknown would appear as missing information. 
Gender of the assailant. The police officers reported the gender of a suspected assailant in the questionnaire according to their observations and the initial questioning of the parties involved at the scene.

Gender of the police. The police and ERC database includes information about the police patrol that was assigned to the call-out, which was used for coding the gender of the officers. There were no police patrols consisting of two female officers and, therefore, the possible gender combinations are two male officers and one female, one male officer.

Recording of an offence. Recording refers to a written record of an offence, which is fundamentally a police response, to distinguish it from victim or third-party reporting to the police. Recording of offences was enquired after within the questionnaire with a simple binary question of whether an offence was recorded or not. Arrest. The variable for arrests was based on the police actions that had been recorded in the police and ERC database by the officers on patrol. The grounds for arrests have to be based on reasons mentioned in the Police Act, and these reasons are connected in the police and ERC data as codes of action in different types of arrests. Two of the most common grounds for arrest included a person being arrested under intoxication and arrested as a suspect to a criminal offence. To examine arrest as a police response to DV, these two codes were recoded as one 'arrest' variable for the analysis.

Informing subjects about support services. The survey included a question on whether the officers provided the subjects with information on DV support services. While police response itself may be limited to restoring the immediate security of the subjects and public as well as investigating whether a crime has been committed, informing involved parties about support organisations and their services can be 
likewise crucial as an intervention to DV. Even though disseminating such information about support services is not an official police response, and consequently has no coding in the ERC and police data systems, police cadets are instructed to inform people about support services in DV cases. Examining whether people are actually being referenced to services could provide possible implications for improving police training and instructions for the police. Whether or not the officers informed subjects was determined by asking 'Did you inform the victim about the following support services?' with the possibility of multiple choices, including social services, two NGOs (the Crime Victim Service [Rikosuhripäivystys] and Family Violence Clinic [Setlementti Naapurin perheväkivaltaklinikka]), Shelter Services, other services, and 'we did not inform anyone about support services.'

Type of violence. The different types of violence are based on police officers' perceptions and answers to the questionnaire about the violent acts that the primary victim experienced with a possibility of multiple choices. The options were based on a scale that is used in the NCVS (e.g. Danielsson \& Kääriäinen, 2017) with the additional choice of verbal aggression and threats. This measure for violence was chosen because both the NCVS and police responsibility on call-outs are focused on acts that constitute criminal offences. Mere threats were excluded from the analysis because in the Finnish Criminal Code, illegal threats are complainant offences and thus not in the scope of the mandatory recording of offences.

The incidents were further categorised into mild physical violence (including stopped from moving or grabbed, pushed or shoved, slapped, and twisted or pulled hair) and severe physical violence (hit with fist, hit with a hard object, kicked or choked, used a weapon including being threatened with a weapon). Some of the acts could not be unambiguously defined as being either mild or severe; therefore, acts that the police 
categorised as 'other physical violence' were recoded as missing from the dichotomised type of violence variable. Sexual violence and attempted sexual violence were excluded from this analysis for several reasons. First, because of the unique dynamics of this type of violence, it would have required defining the focus of the theoretical framework and analysis in this paper more broadly. Second, police call-outs involving sexual offences have a separate categorisation in the exchange of information between the police and ERC because of the different operational requirements and preparations related to them in comparison to DV call-outs. Third, because of the aforementioned categorisation of call-outs, only three cases involving sexual violence or attempted sexual violence were reported in the data.

\section{Results}

The descriptive information about the data is presented in Table 1. In line with previous studies about DV incidents reported to the police, the vast majority $(80 \%)$ of victims in call-outs of this data were women. Correspondently, almost $80 \%$ of the assailants were men. In $2 \%$ of the call-out reports, the gender of the assailant was missing. About $95 \%$ of the victims and $94 \%$ of the assailants were over the age of 18 , indicating that children do not usually call to the police about violence against them, nor do their parents. In $86 \%$ of the cases, violence transpired between partners or ex-partners (including spouses, co-habiting partners, and girlfriends/boyfriends) and in the rest of the cases, other family members and close relatives (not tabulated). Even though couple violence was not examined separately in the final analysis, the proportion of same-sex couples and the association with police response was tentatively examined, as there were 37 same-sex couples in the data. No statistically significant differences were found in police response according to whether the partnership was heterosexual or homosexual. Despite the relatively large minority group size of 37 couples in this sample, it does not 
enable generalisation, as it is too small to be reliably analysed in relation to both police response as well as police and victims' gender combinations.

Police patrols mainly consisted of two male officers; in only $17 \%$ of the callouts did the patrol include both a male and female police officer. For comparison, 14\% of the police officers in the department under examination and $16 \%$ of all police officers in Finland were women in 2015 (PolStat, 2019). Since patrols are sent to tasks on the principle of the nearest available patrol, the dispatch is likely to be random in relation to officer gender.

Table 1. Descriptive statistics of the data $(\mathrm{N}=410)$.

\begin{tabular}{lcc} 
Variable and values & n & \% \\
\hline Gender of the victim & 83 & 20.2 \\
Male & 327 & 79.8 \\
Female & & \\
Gender of the assailant & 324 & 79 \\
Male & 78 & 19 \\
Female & 8 & 2 \\
Missing & & \\
Gender of the police & 334 & 82 \\
Two males & 70 & 17 \\
One male, one female & 6 & 2 \\
Missing & & \\
Type of violence & 212 & 51.7 \\
Mild & 178 & 43.4 \\
Serious & 20 & 4.9 \\
Missing & & \\
Recording of offence & 130 & 31.7 \\
No & 280 & 68.3 \\
Yes & & \\
Arrest & 268 & 65.4 \\
No & 142 & 34.6 \\
Yes & & \\
Informing about support services & 238 & 58 \\
No & 159 & 38.8 \\
Yes & 13 & 3.2 \\
Missing & & \\
\hline
\end{tabular}


Violence was reported to be mild in slightly more than half of the incidents, serious in $43 \%$ of the incidents, and not specified in $5 \%$ of the incidents. In $68 \%$ of the 410 DV call-outs, a criminal offence was recorded. Based on the few indicators that are available for comparison in the police and ERC data, and survey data, this is a focal difference between the two datasets. Of all DV tasks during the data collection period $(\mathrm{N}=1,811)$, in $27 \%$ a criminal offence was recorded, and of all survey-responded tasks $(\mathrm{N}=973)$, the recording rate was $35 \%$. This indicates that the police responded to the survey more often about serious call-outs that gave them a reason to suspect a crime, and that a close relationship between the people involved resulted in even higher recording rate. Arrests were made in a little less than $35 \%$ of call-outs, and referring victims to support services was done in $39 \%$ of call-outs.

As presented in Table 2, the differences in police responses according to gender were generally small to moderate, with the exception of the gender of the victim in association with recording a criminal offence. Recordings of offence were more prevalent in cases involving a female victim (73\%) compared to those involving a male victim (48\%). Differences also exist in the frequency of informing victims about support services, which occurred in $27 \%$ of the call-outs involving a male victim and $44 \%$ with a female victim. Cramer's V indicates a stronger association between the gender of the victim and police response in comparison to the gender of the assailant and police response, so that a female victim and male assailant tended to incur all of the examined police responses more often. No considerable differences were detected in police responses according to the gender of the officer. Differences in recording an offence were statistically significant only for the gender of the victim and assailant. Differences in arrests were not statistically significant, and in informing about support 
services, only differences according to the gender of the victim were statistically significant.

A similar pattern of the victim's gender being important is seen when comparing police recording behaviour with the gender of the victim according to the severity of violence (Table 3). Recording DV as an offence is more prevalent in cases involving female victims (95\%) compared to male victims $(81 \%)$, even when serious physical violence had occurred. Therefore, the severity of the violence does not seem to entirely explain the difference between male and female victims in terms of recording offences. 
Table 2. Police response according to the gender of the victim, the gender of the assailant, and the gender of the police in DV call-outs. \% (n).

\begin{tabular}{|c|c|c|c|c|c|c|c|c|c|c|c|c|}
\hline & \multicolumn{4}{|c|}{ Offence recorded } & \multicolumn{4}{|c|}{ Arrest } & \multicolumn{4}{|c|}{ Informed about support services } \\
\hline & No & Yes & $\mathrm{p}$ & Cramer's V & No & Yes & $\mathrm{p}$ & Cramer's V & No & Yes & $\mathrm{p}$ & Cramer's V \\
\hline \multicolumn{13}{|l|}{ Gender of the victim } \\
\hline Male & $51.8(43)$ & $48.2(40)$ & & & $68.7(57)$ & $31.1(26)$ & & & $73.2(60)$ & $26.8(22)$ & & \\
\hline Female & $26.6(87)$ & $73.4(240)$ & .000 & .22 & $64.5(211)$ & $35.5(116)$ & .478 & .04 & $56.5(178)$ & 43.5 (137) & .006 & .14 \\
\hline \multicolumn{13}{|l|}{ Gender of the assailant } \\
\hline Male & $28.4(92)$ & $71.6(232)$ & & & 64.5 (209) & $35.5(115)$ & & & $59.1(185)$ & $40.9(128)$ & & \\
\hline Female & $46.2(36)$ & $53.8(42)$ & .003 & .15 & $67.9(53)$ & $32.1(25)$ & .567 & .03 & $63.2(48)$ & $36.8(28)$ & .518 & .03 \\
\hline \multicolumn{13}{|l|}{ Gender of the police } \\
\hline Two males & $31.7(106)$ & $68.3(228)$ & & & $64.7(216)$ & $35.3(118)$ & & & $59.9(193)$ & $40.1(129)$ & & \\
\hline One male, one female & $32.9(23)$ & $67.1(47)$ & .855 & .01 & $67.1(47)$ & $32.9(23)$ & 693 & .02 & $58.0(40)$ & $42.0(29)$ & 763 & .02 \\
\hline
\end{tabular}

Table 3. Recording of offences according to victim gender and the severity of the violence, $\%$ (n).

\begin{tabular}{lllll} 
Gender of the victim & \multicolumn{4}{c}{ Offence recorded } \\
& & No & Yes & \\
\hline Male victim & Mild violence & $74.4(32)$ & $25.6(11)$ & $100(43)$ \\
& Severe violence & $18.8(6)$ & $81.2(26)$ & $100(32)$ \\
Cramer's V $=.55$ & & & & \\
Female victim & Mild violence & $43.8(74)$ & $56.2(95)$ & $100(169)$ \\
& Severe violence & $5.5(8)$ & $94.5(138)$ & $100(146)$ \\
Cramer's V $=.44$ & & & & \\
\hline
\end{tabular}


To further examine the associations between police response and victim gender, the combinations of victim and police gender were recoded into a new variable with four categories: female victim and two male officers, female victim and one male and female officer, male victim and two male officers, male victim and one male and one female officer (Table 4). The recording of offences was most common in call-outs involving a female victim and attended by two male police officers and least common in call-outs involving a male victim and two male police officers. Cramer's V (.23) indicates a moderate association between these combinations of victim and police gender in recording offences. Arrest as a police response to DV shows fewer striking differences between gender combinations, and Cramer's V indicates only a minor association between variables. Yet, while arrests occurred most often in call-outs involving a female victim and two male officers, they were almost as common in incidents with a male victim and one male and one female police officer. Informing the victim about support services was least prevalent in call-outs involving a male victim and two male officers, which indicates that gender differences in police response to DV may occur in control actions as well as supportive actions. Differences in the recording of offences and informing about support services were statistically significant. 
Table 4. Police responses to DV according to combinations of victim and police gender, $\%$ (n).

\begin{tabular}{|c|c|c|c|c|c|c|c|c|c|c|c|c|}
\hline & \multicolumn{4}{|c|}{ Offence recorded } & \multicolumn{4}{|c|}{ Arrest } & \multicolumn{4}{|c|}{ Informed about support services } \\
\hline & No & Yes & $\mathrm{p}$ & Cramer's V & No & Yes & $\mathrm{p}$ & Cramer's V & No & Yes & $\mathrm{p}$ & Cramer's V \\
\hline \multicolumn{13}{|l|}{$\begin{array}{l}\text { Combination of victim and police } \\
\text { gender }\end{array}$} \\
\hline Female victim, 2 male officers & $26.0(70)$ & 74 (199) & & & $63.6(171)$ & $36.4(98)$ & & & $55.4(143)$ & $44.6(115)$ & & \\
\hline Female victim, 1 male 1 female officer & $30.2(16)$ & $69.8(37)$ & & & $67.9(36)$ & $32.1(17)$ & & & $59.6(31)$ & $40.4(21)$ & & \\
\hline Male victim, 2 male officers & $55.4(36)$ & $44.6(29)$ & & & $69.2(45)$ & $30.8(20)$ & & & $78.1(50)$ & $21.9(14)$ & & \\
\hline Male victim, 1 male 1 female officer & $41.2(7)$ & $58.8(10)$ & .000 & .23 & $64.7(11)$ & $35.3(6)$ & .813 & .05 & $52.9(9)$ & $47.1(8)$ & .010 & .17 \\
\hline
\end{tabular}




\section{Discussion}

In this study, police responses to DV in one police department in Finland were examined in relation to victims', assailants', and police officers' gender. Due to Finnish legislation and instructions for the police, DV was defined utilising the concept of violence in close relationships, which is a broad concept including both partner violence and violence between children and their parents, yet is somewhat limited to physical assaults.

A notable gender effect was found in the recording of offences. Recording offences was not as common in cases where the assailant was female compared to incidents in which the assailant was male. This finding is supported by another Finnish study in which several legal and extra-legal factors of DV call-outs were included in a multivariate analysis to examine the likelihood of recording an offence; however, no other police responses and gender combinations were analysed (Fagerlund et al., 2018). Even though many related studies have focused on female victims of DV, there are some prior implications of police officers being less likely to implement control actions when the DV disturbance involves a woman inflicting violence on a man (Armstrong et al., 2018; Brown, 2004; Lee et al., 2013). As far as recording of offence is considered a controlling action, this study seems to support those findings.

However, no notable associations between gender and the more commonly studied police response, arrests, were detected in this data. It should be noted that this study was conducted in a jurisdiction and policing environment that does not involve a pro- or mandatory arrest policy, but rather a mandatory recording policy. Overall, the arrest rate was relatively low at $35 \%$ compared to the recording of offences at $68 \%$, which raises questions about the connections between these two police responses. If the police assessed the evidence for a formal recording of offence to be sufficient, what 
could explain that in many of these cases, there was no need or justification for arrest?

The low arrest outcome may be partly explained by situations where the suspected assailant left the premises before the police arrived. This, unfortunately, could not be systematically examined from the data, but based on an overview of incident descriptions, it is not uncommon. Nonetheless, the contradiction between relatively high crime recording rate and low arrest rates ought to be examined further within a similar policy frame of mandatory recording rather than mandatory arrest policy.

Supportive actions were reflected in this study by informing the victim about support services. Being a victim of female gender was associated with more consistently offering information about support services, which adds to prior findings of barriers to men seeking help for DV (Douglas \& Hines, 2011; Huntley et al., 2019). It also reaffirms the concern about gender stereotypes in victimisation to DV (Bates et al., 2019) and is in accordance with the need to examine police response to DV incidents other than those meeting the 'gendered notions of the dynamics' of such violence (Douglas \& Hines, 2011).

The data indicated no clear differences in the simple comparison between police patrols including only male officers and patrols with both a male and female officer in terms of response actions to DV. Based on previous literature, some differences in response to DV could have be expected specifically when looking at supportive police actions to DV rather than in control or coercive actions (Sun, 2007). However, no such associations were found in this study when looking at merely the association between officer gender and informing the victim about support services. Some plausible explanations have been presented: Sun (2007) described female officers as 'willing to "do masculinity" as much as male officers to match the dominant occupational image associated with policing' (p. 591), while Novak and others (2011) posited it in the sense 
that the socialisation to police work as a profession can be more effective than socialisation to a woman.

Analysing combinations of victims' and officers' gender in association with responding to DV brought forth more new insights. Recording of offences and arrests were most common in dyads of female victim and two male police officers. Although with low absolute numbers of incidents, informing the victim about support services was in percentage most common when the victim was male and the call-out was attended by one male and one female police officer. This might indicate importance of female police officers' role in recognition of male victimisation to DV. All three police responses were categorically least likely in call-outs involving a male victim and attended by two male police officers. Thus, from the gender perspective, the combination of a male victim and two male police officers can be seen as a particularly challenging situation for policing DV.

\section{Limitations}

This study has some limitations that should be accounted for before discussing further implications of the results. First, the variables used in this study included police responses and gender indications but excluded other potentially associated factors, such as intoxication and mutuality and repetitiveness of violence, because other factors in relation to recording offences have been examined elsewhere (Fagerlund et al., 2018). Severity of violence in association to the recording of offence was analysed as a third and possibly intervening variable in this setting. The severity of violence could partly explain police responses to DV when taking into consideration prior indications that partner violence by men against women can be more severe in its consequences than violence by women against men. In the current study, recording of offences was more 
prevalent when the victim was female rather than male, even in cases that involved severe physical violence, such as hitting with the fist, hitting with hard objects, kicking, and use of weapons.

Second, without the possibility of identifying the decision-making and response actions in patrols including both female and male police officers, conclusions are limited to the involvement of a female officer. Arguably, the possible influence of a female officer is likely to be more complicated than an analysis of her mere presence might suggest. For example, the age and rank of an officer may be an intervening factor in how the discretion of two police officers in a patrol occurs (Novak et al., 2011). The data analysed here does not enable this type of analysis by officers' age or rank because, with the exception of officer gender, no personal information about the police officers was included in the data. Furthermore, because the original data collection strived for total anonymity of the police officers, and the unit of analysis was a call-out task, there may have been several tasks attended by the same police officers. Therefore, the possibility of personality traits explaining some of the differences found in variation of police response cannot be entirely ruled out.

Finally, even though this study represents a substantial amount of DV call-outs within one major police department area during a six-month data collection period, the data cannot be viewed as representing the whole country. To test whether these findings could be generalised nationally would require large representative samples accompanied by surveys that would considerably strain the police officers on duty. Regardless, the data is a distinctive combination of official police data and survey data concerning the same DV incidents and offers valuable and unique contributions in the Finnish setting. 


\section{Conclusions}

Despite the mandatory recording policy adopted in Finland, which aimed to reduce police discretion in responses to DV, some discretion still remains. The variation in responses seems to be at least partly associated with gender. Victims, assailants, and officers are all socialised into certain conceptions of gender and violence, making gender associations in response to DV likely to be a combination of how the parties of violence themselves perceive violence perpetrated by men and women and how the intervening authority (the police) perceive it. This interpretation is supported by prior findings in a study that utilised the same data, which shows that the most common reason for the police not to record DV as an offence in borderline incidents was that the victim did not want or did not demand it (Fagerlund et al., 2018). Thus, even in a jurisdiction implementing a mandatory recording policy, the police seem to consider the victims' wishes in the decision-making concerning their response to DV.

To add to this, the notion of the police profession being particularly masculine has several implications to policing DV. First, socialisation within patriarchal structures may hinder DV from coming to the attention of the police in the first place and recognising DV as a police matter. Second, the recognition of male victims of DV may be particularly difficult, since male victimisation, especially by a female partner, does not fit into the traditional picture of masculinity. Third, the problematic position of male victims may be even more pronounced when facing the masculine profession of a police officer. Male victimisation to DV by their female partners remains taboo in the general population, to which police officers, being a profession with particularly masculine values, are no exception. This is emphasised in the current study by the finding that the combination of a male victim and two male police officers attending the DV call-out was the least probable incident to result in any of the examined police responses. 
The conclusion here is not suggesting that every DV call-out should result in the recording of an offence or an arrest, but instead point out the possibility that the gender of the victim and the assailant, as well as the officer, and specific combinations of these, may be factors that affect police response to DV. Discretion may not be a problem but the uneven implementation of it is.

In regard to informing victims about support services, the need for discretion seems less evident, as it can be assumed that some form of help is always needed if the police are called in. The importance of this is highlighted in the training of the Finnish police; however, based on the inconsistency of referring victims to support services in this study, there might be room for the further development of practices and continued training for police officers who graduated before the crucial legal reforms and before the mandatory recording policy for DV entered into force.

This study analysed the DV police call-outs of a major Finnish police department, which, taking into consideration the strong prior emphasis on US and UK policing and pro-arrest policies, offers valuable new insights and perspectives into studying police response to DV and policing research internationally as well as to potential policy implications. Information-led policing ought to consider the risks that gendered views may pose in responding to DV. More attention should be paid to gender sensitivity and diversity in police training, with examples of a variety of victims and avoiding gender stereotypes. If DV continues to be defined predominantly as men's violence against (adult) women, the future development of policing and services cannot be expected to be more inclusive for male and child victims nor hold female perpetrators of DV more accountable, for instance. Information about support organisations should be given systematically as part of the frontline response to DV because, as important as mandatory policies for arrests and recording of offences may 
be in the sense of recognising DV as unacceptable at a societal level and as a criminal offence, the criminal procedures might be best accompanied by supporting interventions. The findings of this study are noteworthy for further research, policy formation, and police training that considers the complex associations between genders and policing DV. Similar gender associations concerning frontline police work should be examined in other countries to raise awareness and determine good practices for the equal treatment of victims of DV. 


\section{References}

Aaltonen, M., Salmi, V., \& Kivivuori, J. (2014). Examining offender characteristics in police-recorded domestic violence before and after a legal reform. International Criminal Justice Review, 24(3), 271-284. doi: 10.1177/1057567714548454

Anderson, K. L., \& Umberson, D. (2001). Gendering Violence. Masculinity and Power in Men's Accounts of Domestic Violence. Gender \& Society, 15(3), 358-380.

Arnocky, S., \& Vaillancourt, T. (2014). Sex differences in response to victimization by an intimate partner: More stigmatization and less help-seeking among males. Journal of Aggression, Maltreatment \& Trauma, 23(7), 705-724.

Barrett, B. J., St. Pierre, M., \& Vaillancourt, N. (2011). Police response to intimate partner violence in Canada: Do victim characteristics matter? Women \& Criminal Justice, 21, 38-62. doi: 10.1080/08974454.2011.536057

Bates, E. A., Kaye, L. K., Pennington, C. R., \& Hamlin, I. (2019). What about the male victims? Exploring the impact of gender stereotyping on implicit attitudes and behavioural intentions associated with intimate partner violence. Sex Roles, 81(1-2), 1-15. https://doi.org/10.1007/s11199-018-0949-X

Brown, G. A. (2004). Gender as a factor in the response of the law-enforcement system to violence against partners. Sexuality and Culture, 8, 3-139.

Corradi, C., \& Stöckl, H. (2014). Intimate partner homicide in 10 European countries: Statistical data and policy development in a cross-national perspective. European Journal of Criminology, 11(5), 601-618.

Danielsson, P. \& Kääriäinen, J. (2017). Suomalaiset väkivallan ja omaisuusrikosten kohteena. Kansallisen rikosuhritutkimuksen tuloksia. [Finns as victims of violent and property crimes. Results from the National Crime Victim Survey]. Helsinki: University of Helsinki, Insitute of Criminology and Legal Policy. Danielsson, P. \& Salmi, V. (2013). Suomalaisten kokema parisuhdeväkivalta 2012. Kansallisen rikosuhritutkimuksen tuloksia. [Intimate partner violence experienced by Finnish people 2012. Results of the National Crime Victim Survey 34/2013]. Helsinki: The National Research Institute of Legal Policy.

Davies, P. (2011). Gender, Crime and Victimisation. London: Sage.

Dick, P., \& Jankowicz, D. (2001). A social constructionist account of police culture and its influence on the representation and progression of female officers: A 
repertory grid analysis in a UK police force. Policing: An International Journal of Police Strategies \& Management, 24(2), 181-199.

Dobash, R. P., \& Dobash, R. E. (2004). Women's violence to men in intimate relationships. Working on a puzzle. British Journal of Criminology, 44(3), 324349.

Douglas, E. M., \& Hines, D. A. (2011). The helpseeking experiences of men who sustain intimate partner violence: An overlooked population and implications for practice. Journal of Family Violence, 26(6), 473-485.

Elliffe, R., \& Holt, S. (2019). Reconceptualizing the Child Victim in the Police Response to Domestic Violence. Journal of Family Violence, 34: 589-600.

Fagerlund, M. (2016). Lähisuhdeväkivalta poliisin perheväkivaltatehtävillä. [Violence in Close Relationships and on Police Domestic Violence Call Outs.] Reports of the Police University College 123. Tampere: Police University College.

Fagerlund, M., Kääriäinen, J., \& Ellonen, N. (2017). Recording of Offences on Police Domestic Violence Call Outs. International Journal of Comparative and Applied Criminal Justice. Published online ahead of print, doi: 10.1080/01924036.2017.1364277.

Fagerlund, M., Peltola, M., Kääriäinen, J., Ellonen, N., \& Sariola, H. (2014). Lasten ja nuorten väkivaltakokemukset 2013 - Lapsiuhritutkimuksen tuloksia [Violence against children 2013 - Results of the National Child Victim Survey]. Police University College Reports 110. Tampere: Police University College.

Felson, R. B., Ackerman, J. M., \& Gallagher, C. A. (2005). Police intervention and the repeat of domestic assault. Criminology, 43(3), 563-588.

Felson, R. B., Savolainen, J., Hughes, L. A., \& Ellonen, N. (2015). Gender, provocation, and intimate partner aggression. Partner abuse, 6(2), 180-196.

Frye, V., Haviland, M., \& Rajah, V. (2007). Dual arrest and other unintended consequences of mandatory arrest in New York City: A brief report. Journal of Family Violence, 22(6), 397-405. doi: 10.1007/s10896-007-9094-y

Galdas, P. M., Cheater, F., \& Marshall, P. (2005). Men and health help-seeking behaviour: literature review. Journal of advanced nursing, 49(6), 616-623.

Heiskanen, M. \& Ruuskanen, E. (2011). Men's Experiences of Violence in Finland 2009. Publication Series No. 71. Helsinki: HEUNI. 
Houston, C. (2018). The Trouble with Feminist Advocacy Around Child Victims of Domestic Violence. 39 Women's Rights Law Reporter, (39)85, 85-121. Available at SSRN: https://ssrn.com/abstract $=3351938$

Huntley, A. L., Potter, L., Williamson, E., Malpass, A., Szilassy, E., \& Feder, G. (2019). Help-seeking by male victims of domestic violence and abuse (DVA): a systematic review and qualitative evidence synthesis. BMJ open, 9(6), 1-13.

Johnson, M. P., \& Leone, J. M. (2005). The differential effects of intimate terrorism and situational couple violence: Findings from the National Violence Against Women Survey. Journal of family issues, 26(3), 322-349.

Johnson, M. P. (2010). Langhinrichsen-Rolling's confirmation of the feminist analysis of intimate partner violence: comment on "Controversies involving gender and intimate partner violence in the United States”. Sex Roles, 62(3-4), 212-219.

Jordan, J. (2002). Will any woman do? Police, gender and rape victims. Policing: An International Journal of Police Strategies \& Management, 25(2), 319-344.

Kuoppamäki, S. M., Kääriäinen, J., \& Ellonen, N. (2011). Physical violence against children reported to the police: Discrepancies between register-based data and child victim survey. Violence and victims, 26(2), 257-268.

Langhinrichsen-Rohling, J., Misra, T. A., Selwyn, C., \& Rohling, M. L. (2012). Rates of bidirectional versus unidirectional intimate partner violence across samples, sexual orientations, and race/ethnicities: A comprehensive review. Partner Abuse, 3(2), 199-230.

Lee, J., Zhang, Y., \& Hoover, L. T. (2013). Police response to domestic violence: multilevel factors of arrest decision. Policing: an International Journal of Police Strategies \& Management, 36, 157-174. doi: 10.1108/13639511311302524

MacQueen, S., \& Norris, P. A. (2016). Police awareness and involvement in cases of domestic and partner abuse. Policing and Society, 26(1), 55-76.

Ministry of Justice (2012). The criminal code of Finland (unofficial translation). Helsinki: Ministry of Justice.

National Police Board (2014). Tehtävälajikohtaisia kiireellisyysarvioita ja ohjeita poliisin tehtävien käsittelyssä sekä toimenpidekoodit [Instructions for assignment urgency, processing of assignments and operational codes]. Appendix 2/2014 to the instruction of the National Police Board POL-201410336. 
Novak, K. J., Brown, R. A., \& Frank, J. (2011). Women on patrol: an analysis of differences in officer arrest behavior. Policing: An International Journal of Police Strategies \& Management, 34(4), 566-587.

Piispa, M., Heiskanen, M., Kääriäinen, J. \& Sirén, R. (2006). Naisiin kohdistunut väkivalta 2005 [Violence against women in 2005]. Helsinki, Finland: National Research Institute of Legal Policy/HEUNI.

Prokos, A., \& Padavic, I. (2002). 'There oughtta be a law against bitches': masculinity lessons in police academy training. Gender, Work \& Organization, 9(4), 439459.

Rabe-Hemp, C. (2007). Survival in an "all boys club": Policewomen and their fight for acceptance. Policing: An International Journal of Police Strategies \& Management, 31 (2), 251-270.

Richardson-Foster, H., Stanley, N., Miller, P., \& Thomson, G. (2012). Police intervention in domestic violence incidents where children are present: Police and children's perspectives. Policing and society, 22(2), 220-234.

Robinson, A. L., \& Chandek, M. S. (2000). The domestic violence arrest decision: Examining demographic, attitudinal, and situational variables. Crime \& Delinquency, 46, 18-37.

Sherman, L. W., \& Berk, R. A. (1984). The Specific Deterrent Effects of Arrest for Domestic Assault. American Sociological Review, 49(2), 261-272.

Sun, I. Y. (2007). Policing domestic violence: Does officer gender matter?. Journal of Criminal Justice, 35(6), 581-595.

Straus, M. A., \& Michel-Smith, Y. (2014). Mutuality, severity, and chronicity of violence by father-only, mother-only, and mutually violent parents as reported by university students in 15 nations. Child Abuse \& Neglect, 38(4), 664-676.

Stewart, A., \& Maddren, K. (1997). Police officers' judgements of blame in family violence: The impact of gender and alcohol. Sex roles, 37(11-12), 921-933.

Strom, K. J., Warner, T. D., Tichavsky, L., \& Zahn, M. A. (2010). Policing juveniles: domestic violence arrest policies, gender, and police response to child-parent violence. Crime \& Delinquency, 60(3), 427-450.

Waddington, P. A. (1999). Police (canteen) sub-culture. An appreciation. British journal of criminology, 39(2), 287-309. 
Walby, S., Towers, J., \& Francis, B. (2014). Mainstreaming domestic and gender-based violence into sociology and the criminology of violence. The Sociological Review, 62, 187-214. 